\title{
Tratamiento de unidades léxicas pluriverbales en el DUECh: Observaciones en torno a compuestos y locuciones nominales*
}

\author{
Gabriela Osorio Olave** \\ Universidad de Chile
}

\section{LAS UNIDADES LÉXICAS PLURIVERBALES Y SU INCLUSIÓN EN LOS DICCIONARIOS DE LENGUA}

\begin{abstract}
De acuerdo con Lara $(1990)^{1}$, el diccionario no debe concebirse como un mero centro de acopio de frías definiciones en relación con ciertas voces empleadas en una comunidad particular, sino más bien como un objeto cultural en el que se recogen testimonios de cómo funcionan las lenguas históricas. En efecto, el léxico es aquel componente de las lenguas en que se manifiesta el modo en que los hablantes de determinada comunidad lingüística se apropian de la experiencia, interpretando y categorizando el
\end{abstract}

\footnotetext{
* Esta nota fue escrita en el marco del curso Semántica, dictado por el profesor Alfredo Matus Olivier, en el Programa de Magíster en Lingüística, Mención Lengua Española de la Universidad de Chile.

** Para correspondencia dirigirse a: Gabriela Osorio Olave (gabyosorio@um.uchile.cl), Departamento de Lingüística, Facultad de Filosofía y Humanidades, Universidad de Chile, Ignacio Carrera Pinto 1025, Ñunoa, Santiago, Chile. La autora de esta nota es Becaria de la Comisión Nacional de Investigación Científica y Tecnológica de Chile (CONICYT).

1 Cabe mencionar que en el artículo referido, Lara adopta como objeto de estudio un diccionario de tipo monolingüe y semasiológico. Al igual que el autor, la presente nota se centra en un diccionario de estas características.
} 
mundo que los rodea. De esta manera, resulta lógico que en un diccionario monolingüe de tipo semasiológico tengan cabida no solo i) lexemas univerbales, es decir, unidades léxicas simples -formadas por una única palabra gráfica-, sino que también ii) lexemas pluriverbales, esto es, unidades léxicas formadas por dos o más palabras gráficas, ya que, "desde el punto de vista del contenido, son estas unidades enteras las que funcionan como unidades léxicas, y no los elementos discernibles en sus significantes" (Coseriu 1981: p. 117).

Tales lexías pluriverbales -también denominadas 'expresiones fijas' o 'expresiones complejas', entre otras-corresponden a lo que Coseriu (1981) llama 'discurso repetido', es decir, son trozos de discurso previamente elaborado que se introducen como tales en nuevos discursos. Así, la combinación de palabras que conforma determinada expresión no es producida por el hablante en su acto de habla, sino más bien 'reproducida', ya que dicha combinación se encuentra prefabricada en la lengua': "el hablante se limita a repetirla, en su empleo no hay originalidad"3 (Ferrando Aramo 2002: p. 100).

En vista de lo expuesto, la presencia de las lexías pluriverbales dentro de los diccionarios de lengua no solo se justifica en tanto los diccionarios son los encargados de registrar el léxico de una lengua, sino que su incorporación contribuye a la caracterización de estos últimos como objetos sociales y culturales, poniendo al descubierto numerosos enlaces y visiones de mundo propios de la comunidad lingüística que las emplea. No obstante, su inclusión dentro de los diccionarios de lengua requiere un tratamiento adecuado por parte del lexicógrafo, quién no solo debe atender a la complejísima misión de reconstruir el significado social de tales unidades (Lara 1990: p. 38), sino que también debe someterlas a una clasificación rigurosa y exhaustiva que permita diferenciar las unidades pluriverbales recogidas. Para esto, el lexicógrafo tendrá que establecer ciertos criterios de delimitación, los que deberán ser respetados a lo largo de todo el diccionario, a fin de dotar a la obra de sistematicidad y organización.

Debido a lo anterior, la presente indagación se inscribe dentro del ámbito de la metalexicografía, por cuanto se plantea analizar el tratamiento y, consecuentemente, la clasificación que reciben las unidades pluriverbales en

Este punto explica la estabilidad y fijación característica de dichas unidades.

Se debe ser cauto con esta afirmación, puesto que, si bien es cierto, la combinación de los constituyentes de determinada expresión se encuentra petrificada en la lengua, no es menos cierto que la originalidad del hablante radica precisamente en el empleo y combinación que haga de tal expresión -lexía pluriverbal- con otras unidades del discurso. 
el Diccionario de uso del español de Chile (DUECh, 2010). En particular, nuestra nota se hará cargo de dos tipos de unidades pluriverbales susceptibles de confusión, a saber, compuestos y locuciones nominales, ya que ambas, desde el punto de vista de su estructura, presentan identidad formal. Creemos que una exploración de este tipo puede arrojar luces con respecto al tratamiento que reciben las lexías complejas en los diccionarios de lengua (en nuestro caso, el DUECh) y, al mismo tiempo, contribuir a develar aspectos de la mentalidad y visión de mundo de la comunidad lingüística a la que pertenecemos.

\section{COMPUESTOS Y LOCUCIONES: DOS TIPOS DE UNIDADES FRASEOLÓGICAS}

Las unidades léxicas pluriverbales a las que nos referimos en el apartado anterior ('compuestos' y 'locuciones') forman parte de un dominio mayor conocido con el nombre de 'fraseología'. Siguiendo la propuesta que Corpas Pastor realiza en su Manual de Fraseología Española (1996), entenderemos por unidades fraseológicas (UFS) aquellas "unidades léxicas formadas por más de dos palabras gráficas en su límite inferior, cuyo límite superior se sitúa en el nivel de la oración compuesta" y que se caracterizan por su "fijación y especialización semántica, por su especificidad idiomática y variación potenciales; así como por el grado en el cual se dan todos estos aspectos" ( $p$. 20). De este modo, la autora engloba bajo dicha denominación unidades que funcionan como categorías gramaticales al interior de la oración y también elementos que funcionan como enunciados completos. Sin embargo y de acuerdo con Coseriu (1981), de los elementos señalados solo los primeros tienen cabida en un diccionario de lengua, puesto que son unidades que funcionan como 'lexemas', mientras que los segundos equivalen a 'textemas' o 'frasemas', según la terminología del autor. En relación con estas últimas UFS, señala Coseriu que "el hecho de que a menudo se hallen registradas en los diccionarios de lenguas puede justificarse desde el punto de vista práctico $^{4}$, pero, a pesar de ello, se trata de una incoherencia teórica de la lexicología [y lexicografía] tradicional" (p. 116).

\footnotetext{
4 En nuestra opinión, la escasez de diccionarios fraseológicos y las inquietudes que los usuarios manifiestan ante este tipo de unidades justifican la concesión que el lexicógrafo realiza en virtud de las características y necesidades del destinatario.
} 
Dentro del nivel oracional, Corpas Pastor distingue entre 'colocaciones' y 'locuciones'. A su vez, esta última parcela subsume dentro del término 'locución' tanto a los 'compuestos (sintagmáticos)' como a las 'locuciones' propiamente dichas. No obstante, diferimos de la autora en este punto, puesto que si bien existen propiedades comunes a compuestos y locuciones - en tanto UFS-, también se observan diferencias en el comportamiento de ambos ${ }^{6}$. En este sentido y al igual que muchos estudiosos (García-Page 2001; Ferrando Aramo 2002; Ruiz Gurillo 2002; Zuluaga 2002), abogamos por diferenciar compuestos de locuciones (véase fig. 1).

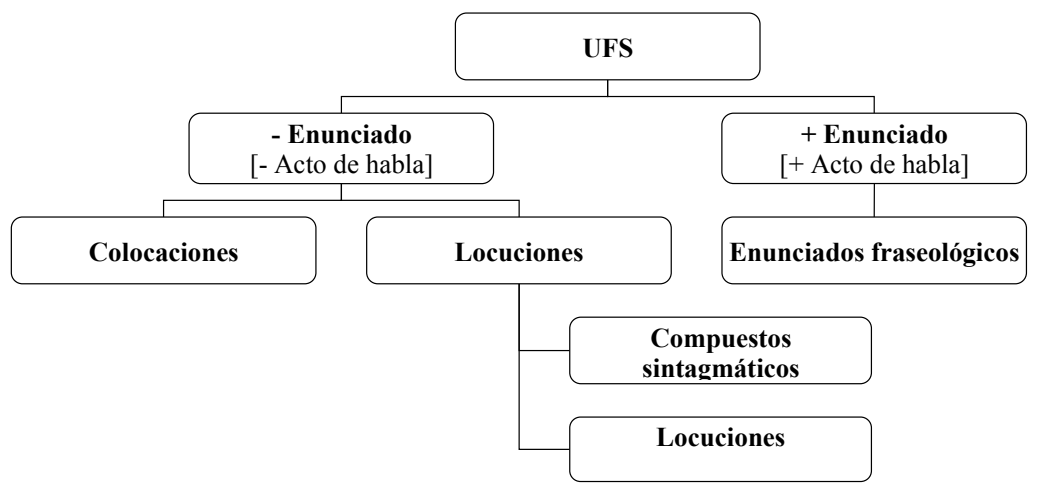

Fig. 1. Esquema de clasificación de las UFS (adaptado de Corpas Pastor, 1996: p. 52)

\section{CONSIDERACIONES METODOLÓGICAS}

El corpus con que se trabajó en esta indagación fue extraído de un total de 2.055 UFS recogidas en el DUECh (2010). De ellas, 618 expresiones corresponden a unidades pluriverbales de tipo nominal, vale decir, un $30,07 \%$ del material fraseológico contenido en el DUECh es de tipo nominal. Por su parte, dentro de dichas unidades nominales se encuentran 264 compuestos y

\footnotetext{
5 Existe una amplia discusión sobre la inclusión o exclusión de las 'colocaciones' respecto del continuum fraseológico. Véase Bosque 2001; García-Page 2001; Ferrando Aramo 2002; Ruiz Gurillo 2002; Zuluaga 2002.

${ }_{6}$ Los resultados obtenidos del análisis efectuado en esta nota apuntan en esta última dirección.
} 
354 locuciones, los que representan un $42,7 \%$ y $57,3 \%$ del total de unidades nominales, respectivamente. Se debe consignar que estas unidades se presentan como entradas independientes en el diccionario y que cuando se trata de locuciones aparecen indicadas con la marca loc. sust.

Para la selección de las unidades sometidas a análisis, se listaron los distintos compuestos pesquisados. De esta manera, a cada compuesto se le asignó un número y luego se generó una tabla de números aleatorios mediante un programa computacional ${ }^{7}$, lo que permitió realizar una selección no intencionada del corpus. Se siguió el mismo procedimiento en el caso de las locuciones.

Cabe precisar que debido a la naturaleza cualitativa y a los alcances de esta nota, el material seleccionado no cumple con las exigencias de representatividad estadística, en relación con el total de unidades pesquisadas. Sin embargo, ello no atenta contra la sistematicidad y rigurosidad del análisis efectuado para cada elemento del corpus.

A partir de lo anterior, se seleccionaron 60 unidades pluriverbales de tipo nominal, de las cuales 30 corresponden a compuestos y 30 a locuciones. Así, se obtuvo el siguiente listado de expresiones sometidas a análisis, según se indica en la tabla 1 y 2.

Tabla 1. Listado de compuestos

\begin{tabular}{|l|l|l|}
\hline \multicolumn{3}{|c|}{ COMPUESTOS } \\
\hline 1. agua perra & 11. hijo, a de tigre (o tigresa) & 21. queso de cabeza \\
\hline 2. ají cacho de cabra & 12. lámpara araña & 22. red seca \\
\hline 3. azúcar flor & 13. libreta de comunicaciones & 23. ropa americana 1 \\
\hline 4. bomba de bencina & 14. maestro chasquilla & 24. sánguche de potito \\
\hline 5. caballo pilchero & 15. maestro, a ciruela & 25. sopas tontas \\
\hline 6. café con piernas & 16. pan de pascua & 26. tuto corto \\
\hline 7. cuchillo cartonero & 17. parche curita 1 & $\begin{array}{l}\text { 27. un dos tres } \\
\text { momia (es) }\end{array}$ \\
\hline 8. cueca brava & 18. pasta base & 28. vale vista \\
\hline 9. desayuno americano & 19. pasta de zapatos & 29. viento blanco \\
\hline 10. hilo curado & 20. pato lile & 30. volantín chupete \\
\hline
\end{tabular}

7 Nos referimos a la herramienta RANDOM.ORG (True Random Number Service), disponible en www.random.org [Consulta: mayo de 2012]. 
Tabla 2. Listado de locuciones

\begin{tabular}{|l|l|l|}
\hline \multicolumn{3}{|c|}{ LOCUCIONES } \\
\hline 1. alto ahí & 11. día del loly & 21. ojito de diuca \\
\hline 2. arrollado primavera & 12. gol de media cancha & 22. patas negras \\
\hline 3. bombita de agua & 13. helado de invierno & 23. pato malo \\
\hline 4. brazo de reina & 14. las casitas & 24. perro judío \\
\hline 5. callejón oscuro & 15. leche asada & 25. pierna suave \\
\hline 6. camino viejo & 16. licor de ave & 26. punto negro \\
\hline 7. canas verdes & 17. loco, a de patio & 27. rienda corta \\
\hline 8. cola de mono & 18. mano de guagua & 28. sabanitas cortas \\
\hline 9. cola fría & 19. marcha blanca & 29. sandía calada \\
\hline 10. colchón de (la) novia & 20. niño envuelto & 30. tole tole \\
\hline
\end{tabular}

\section{RESULTADOS}

Los resultados obtenidos se presentan de manera agrupada, atendiendo a la clase con que las unidades pluriverbales pesquisadas aparecen registradas en el DUECh. De este modo, el presente apartado consta de dos subsecciones: 4.1. Compuestos y 4.2. Locuciones, según se dispone a continuación.

\subsection{Compuestos}

En relación con las lexías pluriverbales clasificadas como compuestos, se debe señalar, en primer lugar, que en todos los casos estas cumplen una función denominativa, esto es, constituyen expresiones que, en su conjunto, permiten aludir a un único referente. Sirva como ejemplo la unidad léxica pan de pascua, en donde, si bien es cierto, se alude a la idea de una preparación que se consume principalmente en la fiesta de Navidad, no se trata de una combinación libre de palabras, puesto que la expresión remite a un referente distinto de 'pan', inscribiéndose más bien en el campo semántico relativo a los 'queques'. Así lo consigna precisamente la definición propuesta por el DUECh para esta entrada: 'producto de repostería elaborado con masa de queque a la que se le añade licor, trozos de fruta confitada y especias, y que se consume especialmente en las fiestas de Navidad'. En este sentido, todas 
las unidades categorizadas como compuestos en el DUECh manifiestan un grado mínimo de no composicionalidad en cuanto a su significado, tal como se refleja en el ejemplo anterior, donde el significado total de la unidad pan de pascua no puede deducirse a partir del análisis de sus partes: 'pan'+ 'de pascua'. Lo mismo ocurre en expresiones tales como agua perra, azúcar flor, cueca brava, entre otras, donde se observa, igualmente, la propiedad de idiomaticidad. Este hecho comprueba que todas las lexías pluriverbales registradas como compuestos en el DUECh corresponden, en primer término, a unidades fraseológicas (UFS) y no a combinaciones libres de palabras, ya que, según comprobó el análisis, en dichas expresiones no se identifica la presencia de ningún núcleo que permita por sí solo aludir al referente ${ }^{8}$, sino que este es designado mediante la expresión en su totalidad (cf. los referentes de pan y pan de pascua).

En segundo término y luego de confirmar el carácter de UFS de las unidades pesquisadas bajo la categoría de los compuestos, se aprecia que todas ellas presentan un equivalente de tipo parafrástico y no univerbal para aludir al referente designado por ellas. De este modo, una lexía como azúcar flor solo permite ser reemplazada por azúcar refinada en polvo. Nótese, además, que en su paráfrasis se distinguen dos elementos relevantes, a saber, un hiperónimo (género próximo) encargado de identificar el dominio semántico dentro del que se inscribe la lexía pluriverbal y, luego, la diferencia específica que permite diferenciarla de otros hipónimos pertenecientes a tal campo. En efecto, la expresión azúcar flor se inscribe dentro del campo relativo a 'azúcar'. Pero pese a pertenecer 'al grupo químico de los hidratos de carbono, de color blanco en estado puro, soluble en el agua y en el alcohol y de sabor muy dulce' (DRAE, s. v. azúcar), posee ciertas características determinadas que la distinguen de otros 'azúcares', a saber, el rasgo [ + refinada]. Así, azúcar flor designa un referente distinto del indicado por azúcar, presentando en este caso, además, un grado máximo de idiomaticidad, puesto que resulta prácticamente imposible para un hablante, en el estado actual de la lengua, descubrir el referente específico que dicha unidad designa a partir de la suma de los significados de 'azúcar' + 'flor'. Lo mismo puede señalarse a propósito de la lexía bomba de bencina, que remite a un tipo específico de establecimiento, tal como se indica en su definición: 'establecimiento donde se vende combustible para vehículos motorizados' (DUECh).

\footnotetext{
8 En los sintagmas libres, por el contrario, se identifican relaciones predicativas entre sus miembros, de modo tal que se reconocen elementos del tipo determinado-determinante(s).
} 
Sin embargo, en relación con la existencia de un equivalente parafrástico, este no solo se presenta como el resultado de la operación reductora de compuestos, sino que también puede ocurrir en el caso de las locuciones. En esta última situación, no obstante, el equivalente parafrástico permite conservar únicamente los rasgos denotativos, esto es, referenciales, del ítem léxico reemplazado, en desmedro de su connotación asociada. De esta manera, la pérdida de efectos expresivos en su reemplazo por un equivalente (parafrástico o no) es una característica típica de las locuciones y no de los compuestos, lo que permite su diferenciación. Nótese que el reemplazo del compuesto caballo pilchero por su equivalente caballo de carga es cualitativamente distinto del reemplazo producido entre la locución hijo, a de tigre (o tigresa) y su paráfrasis hijo que conserva las cualidades elogiables de uno o ambos padres, puesto que dicha locución -hijo, a de tigre (o tigresa) - conlleva una carga valorativa inherente a la lexía en cuestión. En este sentido, si la expresión hijo, a de tigre (o tigresa) connota el rasgo [+ orgullo] por parte de quien lo señala, no solo remite a propiedades denotativas (referenciales), sino que también porta significados connotativos asociados (cf. con la identidad del significado informativo presente en la secuencia caballo pilchero $\rightarrow$ caballo de carga). En relación con aquellas lexías en las que el reemplazo parafrástico conlleva una merma en sus efectos expresivos, el DUECh señala explícitamente dichos valores mediante las marcas de uso espon. y fest., las que dan cuenta precisamente del estilo e intención de tales voces, respectivamente, según indica el diccionario en la sección Indicaciones de uso y marcas (pp. 20-21).

Si consideramos que el reconocimiento de tales valores expresivos e intencionales no es casual, puesto que al reemplazar las entradas que aparecen con dichas marcas por su correspondiente equivalente parafrástico se provoca la pérdida de los valores indicados mediante las marcas de uso, entonces tales voces deberían ser consideradas como locuciones y no como compuestos. Así, la propiedad [+ pérdida de efectos expresivos] se manifestó en 3 unidades pluriverbales, tal como se observa a continuación (tabla 3).

Tabla 3. 'Compuestos' junto con sus marcas de uso (DUECh)

\begin{tabular}{|l|l|l|}
\hline \multicolumn{1}{|c|}{ Entrada } & \multicolumn{1}{|c|}{ Definición } & Marcas de uso \\
\hline $\begin{array}{l}\text { 1. hijo, a de tigre (o } \\
\text { tigresa) }\end{array}$ & $\begin{array}{l}\text { Hijo que conserva las } \\
\text { cualidades elogiables de } \\
\text { alguno de sus padres o } \\
\text { ambos, siendo motivo de } \\
\text { orgullo para ellos. }\end{array}$ & \\
\hline
\end{tabular}




\begin{tabular}{|l|l|l|}
\hline 2. maestro chasquilla & $\begin{array}{l}\text { Persona que tiene por } \\
\text { oficio hacer arreglos } \\
\text { de muy diversa índo- } \\
\text { le. }\end{array}$ & \\
\hline 3. maestro ciruela & $\begin{array}{l}\text { Profesor de enseñanza } \\
\text { básica o secundaria. }\end{array}$ & espon. \\
\hline
\end{tabular}

Un análisis análogo al realizado para la entrada hijo, a de tigre (o tigresa) se puede aplicar a las dos lexías restantes. Así, maestro chasquilla no solo refiere a una 'persona que tiene por oficio hacer arreglos de muy diversa índole', sino que también alude a la idea de que los arreglos efectuados por dicha persona, pese a ser funcionales, son de tipo poco ortodoxo. Este rasgo, [- convencional], se difumina en la paráfrasis correspondiente, a saber, persona que realiza arreglos de diversa índole. Lo mismo cabe señalar para la entrada maestro ciruela, donde su reemplazo por el equivalente profesor (de enseñanza básica o media) conlleva la pérdida de los rasgos simbólicos (connotación) asociados y que dicen relación con la falta de preparación que caracteriza a dicho maestro, de modo que un maestro ciruela no solo refiere a un profesor, sino que también conlleva la carga valorativa negativa propia de una persona que, sin tener la preparación adecuada -[+ ignorante $]-$, realiza tal oficio.

De esta manera, a partir del rasgo [+/- pérdida de efectos expresivos] como resultado del reemplazo de una lexía pluriverbal por su equivalente (parafrástico) correspondiente, se puede señalar que de las 30 unidades examinadas, 27 corresponden a compuestos y 3 a locuciones nominales, los que representan un $90 \%$ y $10 \%$ del total de unidades analizadas, respectivamente. Esta información se entrega de manera resumida en la tabla 4 y en el gráfico 1.

Tabla 4. Resultados: análisis de 'compuestos' nominales

\begin{tabular}{|l|r|r|}
\hline \multicolumn{3}{|c|}{ COMPUESTO } \\
\hline Corresponden & 27 & $90 \%$ \\
\hline No corresponden & 3 & $10 \%$ \\
\hline Total & 30 & $100 \%$ \\
\hline
\end{tabular}




\section{Compuestos}

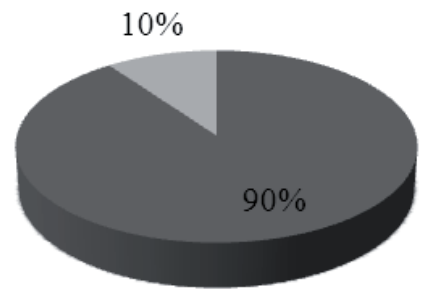

- Corresponden

No corresponden

Gráf. 1. Distribución porcentual de las unidades analizadas

\subsection{LOCUCIONES}

$\mathrm{Al}$ igual que ocurre con los compuestos, respecto a las lexías pluriverbales clasificadas como locuciones se debe señalar que estas cumplen igualmente una función denominativa. Así, las casitas remite al referente 'retrete' y no a 'casa', como pudiera pensarse a partir del análisis de los elementos que conforman tal expresión". Si bien es cierto, la expresión las casitas recibe tal denominación producto de la forma análoga que existe entre el referente designado por aquella -a saber, letrina-y el objeto al que remite el ítem léxico casa, tales expresiones dan cuenta de realidades distintas, lo que las ubica en campos semánticos diferentes. La presencia de la función designativa en cada una de las unidades analizadas justifica su consideración como unidades fraseológicas (UFS) en lugar de interpretarlas como combinaciones libres de palabras.

Pese a lo anterior, en el corpus examinado se observan diferencias en cuanto al comportamiento que tales unidades manifiestan en los respectivos dominios (léxicos) en que se inscriben. Por una parte, se encuentran

9 La ausencia de composicionalidad del significado de la unidad en estudio hace que las casitas goce de un alto grado de opacidad semántica. 
expresiones que permiten su reemplazo por un equivalente parafrástico sin que esto provoque una pérdida en el significado comunicado por la unidad. Así, la expresión brazo de reina permite realizar un análisis similar al efectuado para el compuesto azúcar flor, ya que su reemplazo por la expresión equivalente bizcochuelo plano y alargado cubierto de manjar o mermelada y enrollado sobre sí mismo (véase DUECh) revela que se trata de un tipo de bizcocho (género próximo), pero que, a su vez, posee características que permiten diferenciarlo de otros bizcochuelos (diferencia específica), como lo son los rasgos [+ relleno] y [+ enrollado]. Lo mismo puede señalarse de entradas como arrollado primavera, bombita de agua y callejón oscuro, entre otras, pudiendo identificar en sus paráfrasis respectivas tanto el hiperónimo al que pertenecen como sus rasgos distintivos. Para las voces anteriores, los hiperónimos son 'masa', 'globo' y 'juego', respectivamente, mientras que las propiedades distintivas son $[+$ frita, + cilíndrica, + rellena $] ;[+$ delgado, + con agua $] ;$ y [+ violento, + masculino], en cada caso.

Por otra parte y de manera contraria a lo anterior, el corpus contiene unidades pluriverbales en las que al efectuar la operación reductora de la expresión por un equivalente pluriverbal, se produce una pérdida en el significado informativo comunicado por la expresión, conservándose únicamente los rasgos denotativos y no los valores simbólicos asociados (connotación). Esto se observa en lexías tales como loco, a de patio y mano de monja, donde el reemplazo por persona mentalmente perturbada y habilidad para cocinar, según sea el caso, no alcanza a dar cuenta de la intensificación y valoración (negativa y positiva, respectivamente) que el hablante asocia a cada expresión. La pérdida de dichos significados asociados permite considerar tales unidades como locuciones, en contraste con expresiones como arrollado primavera, bombita de agua, brazo de reina y callejón oscuro, correspondientes, desde este punto de vista, a compuestos.

Continuando con esta línea argumental, junto con la pérdida de efectos expresivos, las locuciones suelen presentar un equivalente de tipo univerbal, según refleja una unidad del tipo patas negras. Esta expresión, definida en el $D U E C h$ como 'persona con la que alguien le es infiel a su pareja', puede ser reemplazada por el equivalente amante. Sin embargo y en tanto locución, son los rasgos culturales de [+ reprobación] los que la convierten en una expresión eufemística de amante, término con el que alterna, dando cuenta ambos de la misma realidad. El mismo valor eufemístico se observa en el mencionado ejemplo las casitas, definida mediante el sinónimo 'retrete' (véase $D U E C h$ ). En este sentido, ciertas locuciones presentan variabilidad 
estilística en relación con sus equivalentes univerbales $\left(\right.$ sinónimos ${ }^{10}$ ), sin embargo, posiblemente sean los efectos expresivos asociados a tales locuciones los que motiven su elección y empleo por parte del hablante en los contextos apropiados.

Resulta interesante el análisis de la expresión día del loly, puesto que el diccionario la define precisamente mediante una locución equivalente, a saber, día del níspero, lo que permite mantener los rasgos connotativos asociados a tal voz. Pese a lo anterior, esta operación implica la remisión a la definición dada para la locución equivalente-día del níspero-, definición en la que se aprecia igualmente la pérdida de efectos expresivos. Así, tanto día del loly como día del níspero conllevan el valor [+ inexistente], rasgo que no se infiere de la definición 'momento muy lejano en el futuro' dada para esta última.

Asimismo, se debe señalar que tal como ocurría respecto a las locuciones clasificadas como compuestos por el DUECh, las locuciones indicadas como tales por este diccionario presentan igualmente marcas de uso - espon. y fest., según sea el caso-. El listado de locuciones con sus indicaciones de uso -marcas- se entregan en la tabla 5.

Tabla 5. 'Locuciones' junto con sus marcas de uso (DUECh)

\begin{tabular}{|l|l|l|}
\hline \multicolumn{1}{|c|}{ Entrada } & \multicolumn{1}{c|}{ Definición } & \multicolumn{1}{c|}{ Marcas de uso } \\
\hline 1. camino viejo & $\begin{array}{l}\text { Tráquea, tubo de las vías } \\
\text { respiratorias que se encuen- } \\
\text { tra entre la garganta y los } \\
\text { pulmones. }\end{array}$ & espon. fest. \\
\hline 2. canas verdes & $\begin{array}{l}\text { Hastío causado por la } \\
\text { repetición de algo molesto } \\
\text { a lo largo de un período } \\
\text { extenso de tiempo. }\end{array}$ & \\
\hline 3. día del loly & Día del níspero. & fest. \\
\hline
\end{tabular}

10 De acuerdo con Seco (1978), se trata de un reemplazo sinonímico "a efectos prácticos" (p. 32), ya que este permite mantener los rasgos denotativos de determinada locución, pero no la connotación asociada a ella. 


\begin{tabular}{|l|l|l|}
\hline 4. gol de media cancha & $\begin{array}{l}\text { Acción con la que se logra } \\
\text { de modo muy hábil y } \\
\text { notable ganarle a alguien } \\
\text { o ponerlo en una mala } \\
\text { situación. }\end{array}$ & \\
\hline 5. las casitas & $\begin{array}{l}\text { Retrete, en especial el de } \\
\text { los colegios. }\end{array}$ & espon. \\
\hline 6. licor de ave & $\begin{array}{l}\text { Bebida alcohólica prepara- } \\
\text { da con vino tinto y gaseosa } \\
\text { de sabor a cola }\end{array}$ & espon. \\
\hline 7. loco, a de patio & $\begin{array}{l}\text { Persona que tiene sus fa- } \\
\text { cultades mentales profun- } \\
\text { damente perturbadas. }\end{array}$ & espon. \\
\hline 8. mano de monja & $\begin{array}{l}\text { Habilidad para cocinar o o } \\
\text { hacer otras labores domés- } \\
\text { ticas. }\end{array}$ & espon. \\
\hline 9. patas negras & $\begin{array}{l}\text { Persona con la que alguien } \\
\text { le es infiel a su pareja. }\end{array}$ & espon. fest. \\
\hline 10. pato malo & $\begin{array}{l}\text { Delincuente que roba de } \\
\text { manera violenta. }\end{array}$ & espon. \\
\hline 11. pierna suave & $\begin{array}{l}\text { Mujer que es la pareja } \\
\text { sentimental de un hombre. }\end{array}$ & espon. fest. \\
\hline 12. sandía calada & $\begin{array}{l}\text { Cosa, asunto o persona } \\
\text { de cualidades conocidas } \\
\text { y que por lo tanto otorga } \\
\text { seguridad o garantías al } \\
\text { acudir a ella. }\end{array}$ \\
\hline & $\begin{array}{l}\text { Situación caracterizada por } \\
\text { la confusión y el desorden. }\end{array}$ & espon. \\
\hline
\end{tabular}

De acuerdo con los rasgos [+ pérdida de efectos expresivos] y, en algunos casos, [+ equivalente univerbal] -consignado o no en la definición-, se puede señalar que de las 30 unidades examinadas, 13 corresponden a locuciones nominales y 17 a compuestos, los que representan un $43 \%$ y $57 \%$ del total de unidades analizadas, respectivamente. La información se presenta en la tabla 6 y en el gráfico 2 . 
Tabla 6. Resultados: análisis de 'locuciones' nominales

\begin{tabular}{|l|r|r|}
\hline \multicolumn{3}{|c|}{ LOCUCIONES } \\
\hline Corresponden & 13 & $43 \%$ \\
\hline No corresponden & 17 & $57 \%$ \\
\hline Total & 30 & $100 \%$ \\
\hline
\end{tabular}

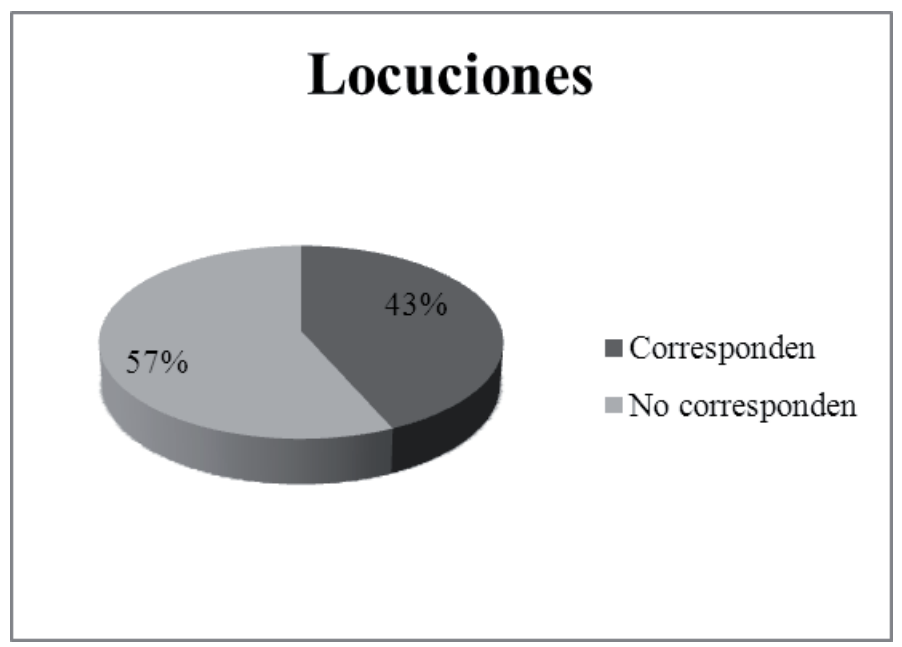

Gráf. 2. Distribución porcentual de las unidades analizadas

\section{CONCLUSIONES}

Luego de examinar las 60 unidades pluriverbales de tipo nominal que componen nuestro corpus, se pueden señalar las siguientes conclusiones generales:

1) Tanto los compuestos como las locuciones registradas en el DUECh corresponden a unidades fraseológicas (UFS) y no a combinaciones libres de palabras. Esto, porque tales expresiones remiten, en bloque, a un referente distinto del que resulta a partir del análisis de sus elementos constituyentes. Esta función designativa explica el carácter idiomático -aunque sea en grado mínimo- de que gozan tales unidades.

2) En relación con los compuestos, la sustitución de estos por un equivalente parafrástico no conlleva una merma de significado, 
manteniéndose los rasgos que permiten identificar el referente aludido. Junto con ello, se debe destacar que todos los compuestos presentan definiciones hiperonímicas, de modo tal que en el definiente (equivalente parafrástico) es posible identificar el ámbito al que determinada unidad pertenece (género próximo), además de sus rasgos distintivos (diferencia específica). A partir de estas propiedades, se observó que de las 30 unidades clasificadas como compuestos por el $D U E C h, 27$ daban cuenta de las propiedades anteriores, lo que representa un $90 \%$ del total de unidades pesquisadas. En el caso de las 30 lexías clasificadas como locuciones, 17 de ellas (57\%) presentaron un comportamiento y tipo de definición idéntico al proporcionado para los compuestos, por lo que se propone su consideración como compuestos y no locuciones.

3) Respecto a las locuciones, el rasgo [+ pérdida de efectos expresivos] permitió su diferenciación de los compuestos. En este sentido, el reemplazo de una locución por su equivalente (univerbal o no) conlleva inevitablemente la pérdida de la connotación asociada. En los casos en que no fue posible efectuar la reducción a un equivalente univerbal, la pérdida de los valores simbólicos se mantuvo constante. Cabe señalar que para todas las unidades que manifestaron tales propiedades, sus artículos lexicográficos presentaban marcas de uso relativas al estilo e intención del hablante. A partir de lo anterior, en el grupo conformado por 30 compuestos se identificaron 3 unidades que funcionan como locuciones, lo que representa un $10 \%$ del total, y en el grupo de las locuciones (30 unidades), solo 13 de ellas cumplían con tales características, lo que corresponde a un $43 \%$ de las ocurrencias.

En vista de lo anterior y tal como señalan algunos autores, creemos que la ausencia de un equivalente univerbal con el que puedan alternar los compuestos probablemente se deba a que la formación de estos "responde a una necesidad de dar nombre, de cubrir una laguna denominativa" (Ferrando Aramo 2002: p. 103) en el plano sincrónico de la lengua (Ruiz Gurillo 2002: p. 333). En las locuciones, por el contrario, la presencia de un equivalente univerbal discernible en la mayoría de los casos o incluso de otras locuciones equivalentes sería "el resultado de procesos de reproducción [...] en la diacronía de la lengua" (p. 333). Esto explicaría que solo locuciones y no compuestos presenten variabilidad estilística, vale decir, la posibilidad de alternar entre distintas formas. La elección del hablante dependería entonces de los rasgos connotativos y no denotativos de la variante empleada.

Con todo, las conclusiones obtenidas en este trabajo son provisionales, puesto que se requiere del examen de un número mayor de casos que los considerados en nuestro estudio. No obstante, el análisis cualitativo efectuado 
revela que siguiendo sistemáticamente ciertos criterios -operativos- como los propuestos se puede conseguir un tratamiento homogéneo, consistente y coherente de las unidades fraseológicas de tipo nominal, a fin de contribuir a la unidad formal que debe tener todo diccionario. En este sentido, la gradualidad de los hechos del lenguaje constituye un imperativo para la adopción de criterios precisos que permitan realizar clasificaciones sistemáticas y coherentes de las unidades pesquisadas. Tales criterios ayudarán no solo al lexicógrafo, indicándole las pautas en base a las que tiene que proceder, sino que también se presentan como una ayuda al lector (destinatario de la obra), quien notará un tratamiento sistemático en el material consultado.

Por último, el examen del material fraseológico revela la complejidad e integridad de los fenómenos del lenguaje, lo que implica y ratifica la existencia de puntos de intersección entre las distintas disciplinas lingüísticas. Consideramos que otras disciplinas, como la gramática, la lexicología y la semántica, pueden contribuir notablemente a perfeccionar el tratamiento del material fraseológico presente en los diccionarios, a partir del establecimiento de criterios operativos que permitan efectuar distinciones claras y precisas entre las unidades del continuum -fraseológico-. Los diccionarios constituyen obras de consulta masiva, y en virtud de esto consideramos que las distintas disciplinas lingüísticas deben aunar esfuerzos.

\section{REFERENCIAS LEXICOGRÁFICAS}

Academia Chilena de la Lengua. 2010. Diccionario de uso del español de Chile (DUECh). Santiago: MN Editorial.

Real Academia Española. 2001. Diccionario de la lengua española (DRAE). Madrid: Espasa Calpe.

\section{REFERENCIAS BIBLIOGRÁFICAS}

Bosque, Ignacio. 2001. Sobre el concepto de “colocación” y sus límites. LEA, XXIII, 1: 9-40. Corpas Pastor, Gloria. 1996. Manual de fraseología española. Madrid: Gredos.

Coseriu, Eugenio. 1981. Principios de semántica estructural. Madrid: Gredos.

Ferrando Aramo, VerónICA. 2002. Colocaciones y compuestos sintagmáticos: dos fenómenos léxicos colindantes. En Pérez Pascual, José Ignacio y Mar Campos Souto (eds.). Cuestiones de lexicografia. Lugo: Tris Tram, pp. 99-107.

García-Page, Mario. 2001. ¿Son las expresiones fijas expresiones fijas? Moenia 7: 165-197. 
Lara, Luis Fernando. 1990. El objeto diccionario. Dimensiones de la lexicografia: A propósito del Diccionario del español de México. México: El Colegio de México, pp. 21-38.

Real Academia Española. 2010. Nueva gramática de la lengua española: Manual (NGLE Manual). Madrid: Espasa Calpe.

Ruiz Gurillo, Leonor. 2002. Compuestos, colocaciones, locuciones: intento de delimitación. En Veiga, Alexandre, Miguel González Pereira y Monserrat Souto Gómez (eds.). Léxico y gramática. Lugo: Tris Tram, pp. 327-339.

Seco, Manuel. 1978 [2003]. Problemas formales en la definición lexicográfica. Estudios de lexicografía española. Madrid: Gredos, pp. 25-26.

Zuluaga, Alberto. 2002. Los "enlaces frecuentes" de María Moliner. Observaciones sobre las llamadas colocaciones. $L E A$, XXIV: 97-114. 